\title{
Ethnic and Immigration Status Differences on Child Indicators of Health for European Americans and Latinos
}

\author{
Christina M. Granillo, David V. Chavez, Donna M. Garcia, and Kelly Campbell \\ California State University San Bernardino
}

\begin{abstract}
This study examined the possibility that ethnicity and immigration status were both related to perceived health and Body Mass Index (BMI) for Latino and European American children. Social identity and comparison theories were used to frame the investigation. A secondary data set comprised of Southern California parents was used for this study. A sample of 165 European American and 152 Latino parents were selected at random and completed a telephone interview about their children's health. Compared to European Americans, Latino caregivers reported poorer general health and higher BMI for their children. Latino children who had a U.S. citizen caregiver reported better health than did Latino children whose caregiver was not a citizen. Our findings add to the literature on differences in health between European American and Latino children living in the USA and highlight how perceptions of children's health may differ based on the ethnicity and citizenship status of the caregiver.
\end{abstract}

(c) 2012 Californian Journal of Health Promotion. All rights reserved.

Keywords: Body mass index, health, ethnicity, children, immigrants

\section{Introduction}

\section{Exploring the Latino Health Paradox among Children}

Children's health is a critical part of development, which can greatly impact health in adulthood. The prevalence of childhood obesity has increased among children ages 6-11 and adolescents (Ogden, Carroll, Curtin, McDowell, Tabak, \& Felgal, 2006). If a child suffers from poor health or childhood obesity, they are more likely to be obese as an adult, have a chronic disease, or a shortened life expectancy (Braveman \& Egerter, 2008). One predictor of child health, including obesity, is racial/ethnic background, with ethnic minority children having poorer overall health outcomes than European American children (Silver, Mijanovich, Uyei, Kapadia, \& Weitzman, 2011). Although this health disparity based on ethnicity is pervasive for African American adults and children, Latinos do not always follow the same pattern. Paradoxical findings emerge for Latinos who fare better than European Americans on a variety of health outcomes including rates of anxiety, mood disorders, substance abuse disorders, lower all-cause mortality rate, and higher life expectancy (Alegria, Canino, Shrout, Woo, Duan, Vila, Torres, Chen, \& Meng, 2008; Abra1do-Lanza, Chao, \& Florez, 2008). This phenomenon is described as the "Latino Paradox." Support for the paradox is inconsistent with regard to children's health. Some researchers find that Latino children are in better health than European American children, whereas others find that they are worse. In this paper, we use the term European American to denote individuals born in the US but with ancestry from European countries and the term Latino to refer to individuals who were either born or have ancestry in Latin American countries.

\section{Health, Obesity, and Latino Children}

Children of Latino descent are now the largest minority group in the U.S. (Fry \& Passel, 2009). Although Latino children are more likely than European Americans to grow up in poverty, their health outcomes do not parallel other ethnic minority children who grow up in poverty. For 
example, African Americans have higher incidences of infant mortality and low birth weight, whereas Latino infants do not (Collins, David, Handler, Wall, \& Andes, 2004). Despite faring better on these particular health measures, Latino children are the same or worse than other ethnic minority children on indicators such as obesity. For example, compared to European Americans, Mexican Americans have higher prevalence of obesity in childhood (ages 6-19 years; $24 \%$ versus $12 \%$ ) and adulthood (34\% versus 29\%) (US Department of Health \& Human Services, 2010).

As noted, the Latino paradox refers to a phenomenon whereby the health of Latino individuals tends to be better than European Americans and empirical findings related to this paradox are mixed (Alegria et al. 2008; Abra1do-Lanza et al., 2008; Centers for Disease Control and Prevention, 2004; Ogden, et al., 2006). The discrepancy across studies could be due to the immigration status of the Latino participants in the different samples. This argument has been termed the Latino immigrant paradox or the healthy immigrant effect (Chen, Martin, \& Matthews, 2006). This proposition is supported by researchers who find that Latino immigrants tend to be in better health than U.S. born Latinos (Acevedo-Garcia, Soobader, \& Berkman, 2007; Oza-Frank \& Narayan, 2010).

The Latino immigrant paradox or the healthy immigrant effect may not have the same results for children as it does for adults, especially related to obesity. For example, Liu, Probost, Harun, Bennett, and Torres (2009) found that adolescent immigrants were more likely than non-immigrants to have a low level of physical activity. Additionally, adolescents from homes in which English is not the primary language have a higher prevalence of obesity. These negative health outcomes for immigrants or children of immigrants were also found for young children. Children aged six to eleven who were first or second generation and non-English speakers were more likely to be obese and less likely to participate in regular physical activity (Taverno, Rollins, \& Francis, 2010). One plausible explanation for these findings is that compared to their parents, the identities of immigrant children and children of immigrants may be more heavily influenced by U.S. cultural norms, which could have negative implications for their health.

\section{Ethnicity and Child Health Disparities}

Health disparities researchers focus on ethnicity because it has consequences for health (Braveman, 2006). Compared to European Americans, ethnic minority children have higher infant mortality rates, lower birth weights, and higher rates of asthma and obesity (Akinbami, Moorman, \& Liu, 2011; Iyasu, Becerra, Rowley, \& Hougue, 1992; Nanyonjoy, Montgomery, Modeste, \& Fujimoto, 2008; Ogden, Flegal, Carrol, \& Johnson, 2010). The obesity rates of Latinos as young as four years old exceed those of European and African American children of the same age (Ogden, Carroll, Curtin, McDowell, Tabak, \& Flegal, 2006). In general, Latino children are more likely to have fair or poor health (Flores, Bauchner, Feinstein, \& Nguyen, 1999).

\section{Determinants of Obesity}

Various factors influence the likelihood of childhood obesity including family dynamics, food choices, and the built environment. Family dynamics such as the extent to which parents are involved in their children's lives can influence obesity. Specifically, parental involvement at meal time and their communication during meal times have both been found to be related to control over children's food intake (Olstad \& McCargar, 2009) as well as the child's weight (Washington, Reifsnider, Bishop, Ethington, \& Ruffin, 2010).

Although parents strongly influence the food habits of their children, with age, children gain autonomy over their food choices and rely less on the home environment (Rockett \& Colditz, 1997). However, children's diets tend to be poor, whether in the home or away from home. In the United States, only two percent of children eat a recommended diet (Batada \& Wootan, 2007). For example, children often eat foods with high amounts of fat and sugar (Rockett \& Colditz, 1997; Cusatis \& Shannon, 
1996) and rarely eat preferable amounts of fruits and vegetables (Fisher \& Birch, 1999).

A third factor influencing obesity in children is physical activity. Many children are classified as insufficiently active (Nelson, Carpenter, \& Chiasson, 2006) and inactivity increases with age (Saelens, Sallis, Nader, Broyles, Berry, \& Taras, 2002). Children who spend more time inactive or in sedentary activities have been found to have both unhealthy diets and higher BMIs (Bukara-Radujkovic \& Zdravkovic, 2009; Harris, Bargh, \& Brownell, 2009). Children cannot make healthy choices about play if they do not have the access or opportunity for physical activity. Additionally, place affects behavior, and in turn, health (Frumpkin, 2003). Children need access to safe play in order to engage in activities that will positively impact their health. Multiple built environment factors have been found to influence the physical activity of young children and adolescents (Ding, Sallis, Kerr, Lee \& Rosenberg, 2011).

Social Comparison and Social Identity Theories Both social comparison and social identity theories can be used to elaborate on the complicated relationship between immigrant status and health outcomes. According to social comparison theory, individuals draw comparisons between themselves and similar others in order to evaluate their sense of wellbeing and worth (Suls, Martin, \& Wheeler, 2002). Social identity theorists (Tajfel \& Turner, 1986) argue that these comparisons are meaningful at the group as well as individual level because the self-concept is derived from group memberships, rather than solely personal attributes. When individuals from low-status groups (i.e., low income, ethnic minorities) compare themselves upwards to high-status groups (i.e., high income, ethnic majority), they are more likely to experience feelings of devaluation (Garcia, Branscombe, Desmarais, \& Gee, 2006), which could adversely affect health (Campbell, Garcia, Granillo, \& Chavez, 2012).

Although these theories would predict that ethnic minorities might experience poor health due to upward comparisons with the ethnic majority, an exception pertains to immigrant populations in the U.S. People who are born outside the U.S. may not compare themselves to the American ethnic majority, and may instead make downward comparisons to people from their countries of origin (Wolf, Acevedo-Garcia, Subramanian, Weber, \& Kawachi, 2010). In such cases, immigrant populations may perceive better health outcomes for two reasons. First, immigrants may not be fully aware of or concerned about their devalued status. Second, when using individuals in their home countries as their frame of reference, immigrants are likely to be aware that their standard of living is higher, and these downward comparisons could enhance their self-esteem, which can buffer the effects of stress on health (Campbell et al., 2012; Rector \& Roger, 1997).

The above reasoning suggests that the Latino paradox may apply more to adults than children. Although the health behaviors of children may be dictated to some extent by their parents, their social comparisons, whether conscious or not, might be heavily influenced by their peers. Because they have more contact with the dominant culture through the school system, children likely use European Americans as a reference group. These upward comparisons with the ethnic majority would cause them to be more aware of their group's devalued status, which would negatively impact health. For ethnic minority children, this finding is expected regardless of their immigration status, unlike the processes that would occur for their immigrant parents. Children of Latino immigrants rather than citizens, however, may demonstrate the worst outcomes due to feelings of devaluation resulting from such upward social comparisons.

\section{The Current Study}

The literature is unclear if Latino children of immigrants follow the same healthy immigrant or Latino paradox as their parents. This study was conducted to investigate whether children of immigrants showed more positive outcomes than children of U.S. born parents. The following specific hypotheses were examined:

1)Caregivers will perceive the BMI and general health of Latino children or children with a Latino American caregiver as worse relative to 
those with a European American caregiver. Consistent with social comparison theory, we expect that children draw comparisons between themselves and their peers to establish their social value. Because such comparisons would be unfavorable for Latino children, they would experience stress, which would impair their health outcomes, and result in negative health appraisals from their caregivers. Indeed, although the research is mixed in terms of whether Latinos fare better or worse than European Americans in terms of BMI and health, Latino children tend to exhibit higher BMI (e.g., Ogden et al., 2006) and poorer overall health (e.g., Flores et al., 1999).

2)If the Latino Paradox does not apply to immigrant children, among Latinos, the reported BMI scores will be higher and the general health scores will be lower for children with immigrant caregivers compared to children with nonimmigrant caregivers. This finding would be consistent with the existing empirical literature (e.g., Liu et al., 2009) regarding the Latino Paradox, as well as social identity and comparison theories.

\section{Methods}

\section{Procedure}

The data were originally collected by the Health Assessment Resource Center (HARC), and the authors obtained permission to use the data for the current study. Complete information about the methods used for data collection is available at http://www.harcdata.org. Over 55,000 individuals who were living in the east Riverside County of southern California were contacted for a telephone interview using random digit dialing (RDD) in order to ensure 3,150 individuals who met the inclusion criteria completed the survey. This method ensured that all telephone-equipped households were included in the sample. If individuals reported having a child living in the home, interviews were conducted with a parent or guardian who reported being knowledgeable about the child's general health care. Computer assisted telephone interviewing (CATI) software was utilized to administer the survey. Only the measures used for the present investigation are described below. IRB approval for this study was obtained from the authors' university committee.

\section{Participants}

Participants responded to questions about their demographic characteristics and their child's demographic characteristics, including gender (self and child), ethnicity (self and child), age (self and child), and immigration/citizen status (self). To test our hypotheses, we extracted only those respondents who self-identified as European American (or White) and Latino or Hispanic and who met several conditions. First, they needed to identify one child (between age 0 and 17) in their household and be a caregiver of that child. A caregiver could be any person whose role to the child included being a biological, adoptive or foster parent, grandparent, or legal guardian. A second condition of inclusion was that the respondent answered all relevant questions regarding the age, weight, and height of the child and gave a perceived general health rating for the child. The third condition was that the given age, height, and weight information corresponded with values on the CDC child growth and BMI charts. We only retained cases with height and weight estimates that produced BMI scores based on the Centers for Disease Control and Prevention (CDC) age-height-weight range. According to the CDC, the expected BMI scores of children (between 0 and 17) range between 12 (5th percentile) to 34 (95th percentile). Because of possible exceptions and estimation errors, we extended the range to include scores from the HARC data that rounded to one point above or below the typical range (i.e., from 10.5 to 35.4).

No information about specific place of origin was available in the data set; thus, the determinations of ethnicity were based solely on the respondent's self-identification or identification of themselves and their children as White (which we classified as European American) or Latino/Hispanic. Latino caregivers and children were further divided into two categories that included Latino caregivers who were American citizens in one group and Latino caregivers who were not American citizens in the other. Altogether, there were 165 European American and 152 Latino caregivers who met 
the inclusion criteria. Of the Latino caregivers, 105 indicated that they were U.S. citizens and 42 indicated that they were not.

\section{Outcome Measures}

Body Mass Index (BMI). BMI was calculated by dividing the reported child's weight by child's height. BMI is one of the more common mechanisms for assessing obesity and an established correlate of illness (Wang \& Beydoun, 2007).

Perceived general health. In order to assess perceived general health, participants responded to the following question "In general, would you say [insert child's name]'s health is: Excellent (1), Very Good (2), Good (3), Fair (4), or Poor (5)?" Self-rated health assessments have been shown to provide accurate estimations of health status (Jylha, 2009).

Ethnicity and status. To create the variable "Caregiver Ethnicity and Status" we combined caregiver ethnicity and status such that caregivers of children were divided into three categories: caregivers who identified as European or "White" American citizens (coded as 1), caregivers who identified as Latino American citizens (coded as 2), and caregivers who identified as Latino and did not have American citizenship (coded as 3). The purpose of categorizing the data into these three groups was to examine whether the health of children differed based on ethnicity (for European American and Latino children) and citizenship (for Latino children) of their caregivers. We did not include a category of European American non-citizens because there were too few respondents $(n=6)$ who met these criteria.

Analytic Plan. To test our hypotheses, we ran one set of one-way analyses of variance (ANOVAs) on the two health-outcome variables, and then used planned comparisons to compare each of the three groups. We could not assess the variables in a single 2 (Parent Ethnicity: European or Latino) x 2 (Caregiver Status: Citizen or Non-citizen) factorial ANOVA because (as noted above) too few European American respondents were noncitizens $(n=6)$. To overcome this issue, we ran the analyses with "Caregiver Ethnicity and Status" as a 3-level factor (Caregiver: European American citizen, Latino American citizen, and Latino non-citizen). For ease of comparison, we report the results for BMI first followed by the same set of results for perceived general health. We chose to use ANOVA rather than regression for two key reasons. First, our predictor variables were categorical and not continuous. Second, because we had a 3-level variable, ANOVA allowed us greater flexibility in testing comparisons. With ANOVA we could compare all three levels to each other. With regression, we could only compare either both Latino groups to the European American group (via dummy coding) or both Latino groups to the European American group then to each other (via contrast coding). Although one could anticipate that child sex and age would be important covariates in the analyses, preliminary analyses indicated that sex was not significant for BMI, $\mathrm{t}=.94, \mathrm{p}=.351$, or perceived general health, $\mathrm{t}=-1.56, \mathrm{p}=.12$, and age was a significant covariate for BMI, $t=5.71, p<.001$, but only marginally significant for perceived general health, $t=1.92, p=.056$. The nature of the relationship between age and the outcome measures was as age increased, BMI increased and perceived general health became less positive. Because these covariates were not consistent contributors to the model and had minimal impact on the overall results (as shown in preliminary analyses), we chose to not include them in the analyses and continued with our analytic plan to use ANOVA. Significance levels were set at $\mathrm{p}<.05$ for all analyses, including planned comparisons. Differing degrees of freedom between the two outcome measures reflect the tendency for caregivers to not always provide the information needed to calculate the child's BMI (i.e., weight and height).

\section{Results}

\section{Characteristics of the Participants}

Caregiver ethnicity and status. The European American group (103 women, 62 men) were all U.S. citizens and ranged in age from 18 to 70 years (Median $=42$ years). Of these individuals, a majority $(45 \%)$ had at least a Bachelors 
degree. All European Americans indicated they were U.S. citizens. In the Latino citizen group (68 women, 37 men), the age ranged from 18 to 83 years (Median $=46$ years) and fewer participants (18\%) had a Bachelors degree or higher. In the Latino non-citizen group (31 females and 16 males), the age ranged from 24 to 58 (Median $=42$ ) and 2 percent had received a Bachelors degree or higher.

\section{Main Analyses}

Body mass index. The omnibus test for the oneway ANOVA examining the relationship between Caregiver Ethnicity-and-Status and reported BMI was significant, $\mathrm{F}(2,314)=7.97$, $\mathrm{p}<$. 001. Planned comparisons between the three means (see Table 1) showed that as expected, the reported BMI scores were lower for children with European American citizen caregivers than were those for children with Latino caregivers, regardless of whether the Latino caregiver respondent self-identified as an American citizen, $\mathrm{t}(314)=-3.60, \mathrm{p}<.001, \mathrm{~d}=$ .41 , or a non-citizen, $\mathrm{t}(314)=-2.71, \mathrm{p}=.007, \mathrm{~d}$ $=-0.31$. Within the Latino caregiver group, the reported BMI scores of children were the same regardless of whether the caregiver selfidentified as a U.S. citizen or as a non-citizen, $\mathrm{t}(314)=-0.01, \mathrm{p}=.993$, ns. Overall, the analyses demonstrated that children who had a European American caregiver tended to have lower BMI scores than did children who had a Latino caregiver, regardless of whether or not the caregiver respondent was a U.S. citizen. Thus, our first hypothesis about BMI was supported, but our second hypothesis was not supported.

\section{Perceived General Health}

The omnibus test for the one-way ANOVA examining the relationship between Caregiver Ethnicity and Status and perceived general health was significant, $\mathrm{F}(2,314)=19.88, \mathrm{p}<$. 001. Planned comparisons between the three means (see Table 1) showed that as expected, European American citizen caregivers assessed children's health more positively than did both Latino citizen, $\mathrm{t}(314)=-3.15, \mathrm{p}=.001, \mathrm{~d}=-$ 0.36 , and Latino non-citizen, $\mathrm{t}(314)=-6.15, \mathrm{p}<$ $.001, \mathrm{~d}=-0.69$, respondents. Within the Latino caregiver group, citizens reported that the child in their household had better health than did the non-citizens, $\mathrm{t}(314)=-3.55, \mathrm{p}<.001, \mathrm{~d}=-0.40$. Overall, the analyses demonstrated that if either the caregiver or child was European American, the child was subjectively assessed as having better health than if the child was Latino, regardless of the citizenship of the caregiver respondent. However, if either the caregiver or the child were Latino, citizens assessed the health of the child more positively than did noncitizens. Together, these analyses suggest that children who are European American or have a European American caregiver are perceived as having better health than are children who are Latino (as per Hypothesis 1). Further, Latino children with a citizen caregiver are perceived to be faring better health-wise than are those who have a non-citizen caregiver by their caregiver (as per Hypothesis 2).

Table 1

\begin{tabular}{|c|c|c|c|c|c|c|}
\hline \multicolumn{7}{|c|}{$\begin{array}{l}\text { Children's health as a function of caregiver } \\
\text { ethnicity and citizenship }\end{array}$} \\
\hline & \multicolumn{2}{|c|}{$\begin{array}{c}\text { White } \\
\text { Citizen } \\
\text { Caregiver }\end{array}$} & \multicolumn{2}{|c|}{$\begin{array}{c}\text { Latino } \\
\text { Citizen } \\
\text { Caregiver }\end{array}$} & \multicolumn{2}{|c|}{$\begin{array}{c}\text { Latino } \\
\text { Non-Citizen } \\
\text { Caregiver }\end{array}$} \\
\hline & $\mathrm{M}$ & SD & M & SD & M & SD \\
\hline $\begin{array}{l}\text { Body Mass } \\
\text { Index }\end{array}$ & $1.60_{\mathrm{a}}$ & 0.76 & $1.95_{\mathrm{b}}$ & 1.01 & $2.51_{b}$ & 1.06 \\
\hline $\begin{array}{l}\text { General } \\
\text { Health }\end{array}$ & \multicolumn{2}{|c|}{$\begin{array}{c}20.01_{\mathrm{a}} \\
4.36\end{array}$} & \multicolumn{2}{|c|}{$\begin{array}{c}22.23_{\mathrm{b}} \\
5.46\end{array}$} & \multicolumn{2}{|c|}{$\begin{array}{c}22.22_{\mathrm{c}} \\
5.60\end{array}$} \\
\hline
\end{tabular}

Note: Means in the same row with different subscripts differ at $p<.05$

\section{Discussion}

In this study, we examined how ethnicity and citizenship status related to children's BMI scores and general health. Compared to children with European American caregivers, those with Latino caregivers were more overweight/obese, as evidenced by higher BMI scores. This finding was expected and consistent with previous research that reports poorer health for Latino children (Maalouf-Manasseh, MetallinosKatsaras, \& Dewey, 2011). Irrespective of their 
caregiver's citizenship status, children with Latino caregivers did not show improvements in BMI scores compared to those with European American caregivers. Therefore, we did not find support for transmission of the healthy immigrant effect in that parent's citizenship status did not relate to children's objective health, specifically their weight. We also did not find the expected reverse effect that Latino children would have higher BMI when their caregiver was an immigrant rather than a citizen.

In regards to perceived general health, it was hypothesized that children with European American caregivers would receive better ratings from their caregivers than those with Latino caregivers. Additionally, children with Latino caregivers who were immigrants were expected to receive poorer general health ratings than children whose Latino caregivers were citizens. The results supported our hypothesis for children of European American caregivers. European American children received better general health ratings than did Latino children. Also consistent with expectations, children whose parents were Latino and citizens received better general health ratings than did children whose parents were Latino but not citizens.

Based on the results from this study, it appears that immigrant parents' perceptions of their child's health are not determined by making comparisons with people from their country of origin. Instead, parents may be evaluating their children's weight and health with respect to other children in the U.S. Alternately, parent's assessments might be reflective of their children's actual health, which is determined, in part, by the social comparisons those children make about their social value. It would be worthwhile for future research to investigate these variables from the perspective of the child. Such research could help identify Latino children's reference groups, including how their social comparisons impact health.

\section{Limitations}

Although our study contributes valuable information about Latino health in the U.S., some limitations should be noted. A major limitation is that the archival dataset did not contain data on the immigration status of the children in the study. We only had information about the status of one caregiver, which limits the interpretation of our findings. It is likely that the status of all primary caregivers contribute to the children's health. Another limitation is related to the self-report nature of the study. The meaning of general health could vary across cultural groups and, as suggested above, may be affected by caregivers' beliefs about ideal weight. Also, BMI was calculated by dividing self-reported weight by self-reported height. Although some researchers have found such reports to be reliable (Kuczmarski, Kuczmarski, \& Najjar, 2001), other have found them less reliable (e.g., Taylor, Dal Grande, Gill, Chittleborough, Wilson, Adams, et al., 2006). In our study, we needed to eliminate some data because the reported BMI scores were outside of a possible range. The potential problem associated with self-reported weight and height indicates that deriving a BMI based on this selfreport data is not an ideal measure of health. Finally, although Random Digit Dialing (RDD) methods are advantageous because they allow for representative samples to be gathered quickly, the technique may lead to nonresponse bias for certain individuals, such as those from low economic status (ES) populations. However, if our sample had included greater numbers of individuals from a low ES population, we believe the results would have been more robust, rather than different.

\section{Implications}

Despite these limitations, our study provides new information on Latino children's BMI and parental reports of general health, which is important considering the limited number of studies on Latino children. This study highlights the need for more research on the health of Latino families, particularly because they represent a heterogenous group with respect to various factors including immigrant status and country of origin. Such complexities likely account for some of the discrepant findings related to Latino children and health. Our results suggest that within the Latino population, children of immigrants may be at heightened risk for experiencing poor health outcomes. Finding ways to help immigrant parents 
Granillo, C. M., Chavez, D. V., Garcia, D. M., \& Cambell, K. / Californian Journal of Health Promotion 2012, Volume 10, Special

Issue II: Health Disparities on Latino Communities, 15-24

maintain good health and teach healthy behaviors to their children can result in lower incidence of childhood obesity and related health outcomes.

\section{Acknowledgements}

The work on this paper was funded by a grant from the National Institute of Minority Health and Health Disparities (5 P20 MD 002722). Data were provided by the Health Assessment
Resource Center (HARC), in Eastern Riverside County, CA, Palm Desert. Any mistakes in the analyses, presentation of information, or content of the publication/presentation are the sole responsibility of the authors and not the HARC Organization. The authors would like to specifically acknowledge Sybil Carrere, Dale Lund, Shelley Osborn, and Eileen Packer for their help with data management and feedback on earlier drafts.

\section{References}

Akinbami, L., Moorman, J., \& Liu, X. (2011). Asthma prevalence, health care use, and mortality: United States, 2005-2009. National Health Statistics Report, 12(32), 1-14.

Abraido-Lanza, A. F., Chao, M. T., \& Florez, K. R. (2008). Do healthy behaviors decline with greater acculturation?: Implications for the Latino mortality paradox. Social Science and Medicine, 61, $1243-1255$.

Acevedo-Garcia, D., Soobader, M.-J., \& Berkman, L. F. (2007). Low birthweight among Hispanic/Latino subgroups: The effect of maternal foreign-born status and education. Social Science and Medicine, 65, 2503-2516.

Alegria, M., Canino, G., Shrout, P. E., Woo, M., Duan, N., Vila, D., Torres, M., Chen, C-N., \& Meng, XL. (2008). Prevalence of mental illness in immigrant and non-immigrant U.S. Latino groups. American Journal of Psychiatry, 165, 359-369.

Batada, A. \& Wootan, M. G. (2007). Nickelodeon markets nutrition-poor foods to children. American Journal of Preventative Medicine, 33, 48-50.

Braveman P. (2006). Health disparities and health equity: Concepts and measurement. Annual Review of Public Health 2006, 2,167-194.

Braveman, P. \& Egerter, S. (2008). Overcoming obstacles to health: Report from the Robert Wood Johnson Foundation to the Commission to Build a Healthier America. Robert Wood Johnson Foundation, 1-80.

Bukara-Radujkovic, G. \& Zdravkovic, D. (2009). Physical activity as an important determinant in developing childhood obesity. Med Pregl, 62, 107-113.

Campbell, K., Garcia, D. M., Granillo, C. M., \& Chavez, D. (2012). Exploring the Latino Paradox: How Economic and Immigration Status Impact Health. Hispanic Journal of Behavioral Sciences, 34 (2), 187-207.

Centers for Disease Control and Prevention. (2004). The burden of chronic diseases and their risk factors: National and state perspectives 2004. Atlanta: U.S. Department of Health and Human Services; 2004. Available at: http://www.cdc.gov/nccdphp/burdenbook2004.

Chen, E., Martin, A., \& Matthews, K. (2006). Understanding health disparities: the role of race and socioeconomic status in children's health. American Journal of Public Health, 96, 702-708.

Collins, J., David, R., Handler, A., Wall, S., \& Andes, S. (2004). Very low birth weight in Black infants: The role of maternal exposure to inter-personal racial discrimination. American Journal of Public Health, 94, 2132-2137.

Cusatis, D. C., \& Shannon, B. M. (1996). Influences on adolescent eating behavior. Journal of Adolescent Health, 18, 27-34.

Ding, D., Sallis, J. F., Kerr, J., Lee, S., \& Rosenberg, D. E. (2011). Neighborhood environment and physical activity among youth: A review. American Journal of Preventative Medicine, 41, 442-455.

Fisher, J. O. \& Birch, L. L. (1999). Restricting access to foods and children's eating. Appetite, 32, 405419. 
Granillo, C. M., Chavez, D. V., Garcia, D. M., \& Cambell, K. / Californian Journal of Health Promotion 2012, Volume 10, Special

Issue II: Health Disparities on Latino Communities, 15-24

Flores G, Bauchner H, Feinstein A, Nguyen U. (1999). The impact of ethnicity, family income, and parental education on children's health and use of health services. American Journal of Public Health, 89, 1066-1071.

Frumpkin, H. (2003). Health places: exploring the evidence. American Journal of Public Health, 93,1451-1456.

Fry, \& Passel, (2009). Latino children: A majority are U.S.-born offspring of immigrants. Washington DC: Pew Hispanic Center.

Garcia, D. M., Branscombe, N. R., Desmarais, S., \& Gee, S. S. (2006). The effects of social comparisons and policy experience on attitudes toward redistributive social policies. In S. Guimond (Ed.), Social comparison and social psychology: Understanding cognition, intergroup relations and culture (pp. 151-173). Cambridge, UK: Cambridge University Press.

Harris, J. L., Bargh, J. A., \& Brownell, K. D. (2009). Priming effects of television food advertising on eating behavior. Health Psychology, 28, 404-413.

Iyasu, S., Becerra, J., Rowley, D., \& Hougue, C. (1992). Impact of very low birth weight on the black-white infant mortality gap. American Journal of Preventive Medicine, 8, 1333-1347.

Jylha, M. (2009). What is self-rated health and why does it predict mortality? Towards a unified conceptual model. Social Science \& Medicine, 69, 307-316.

Kuczmarski, M.F., Kuczmarski, R. J., \& Najjar, M. (2001). Effects of age on validity of selfreported height, weight, and body mass index: Findings from the Third National Health and Nutrition Examination Survey, 1988-1994. Journal of the American Diet Association, 101, 28 34.

Liu, J., Probst, J., Harun N, Bennett, K., Torres, M. (2009). Acculturation, physical activity, and obesity among Hispanic adolescents. Ethnic Health, 14, 509-525.

Maalouf-Manasseh, K., Metallinos-Katsaras, E., \& Dewey, K. (2011). Obesity in preschool children is more prevalent and identified at a younger age when WHO growth charts are used compared with CDC charts. Journal of Nutrition, 141, 1154-1158.

Nanyonjoy, R., Montgomery, S., Modeste, N., \& Fujimoto, E. (2008). A secondary analysis of race/ethnicity and other maternal factors affecting adverse health outcomes in San Bernardino County. Maternal Child Health Journal, 12, 435-441.

Nelson, J. A., Carpenter, K. \& Chiasson, M. A. (2006). Diet, activity, and overweight among preschool-age children enrolled in the special supplemental nutrition program for Women, Infants, and Children (WIC). Preventing Chronic Disease, 3, A49.

Ogden, C. L., Carroll, M. D., Curtin, C. L., McDowell, M. A., Tabak, C. J. \& Flegal, K. M. (2006). Prevalence of overweight and obesity in the United States, 1999-2004. Journal of the American Medical Association, 13, 1549-1555.

Ogden, C. L., Flegal, K. M., Carroll, M. D., \& Johnson, C. L. (2010). Prevalence and trends in overweight among U.S. children and adolescents, 1999-2000. Journal of the American Medical Association, 14, 1728-1732.

Olstad, D. L. \& McCargar, L. (2009). Prevention of overweight and obesity in children under the age of 6 years. Applied Physiology Nutrition Metabolism, 34, 551-570.

Oza-Frank, R., \& Narayan, K. M. V. (2010). Overweight and diabetes prevalence among U.S. immigrants. American Journal of Public Health, 100, 661-668.

Rector, N., \& Roger, D. (1997). The stress buffering effects on self-esteem. Personality and Individual Differences, 23, 799-808

Rockett, H. R. \& Colditz, G. A. (1997). Assessing diets of children and adolescents. American Journal of Clinical Nutrition, 65, 1116S-1122S.

Saelens, B. E., Sallis, J. F., Nader, P. R., Broyles, S. L., Berry, C. C. \& Taras, H. L. (2002). Home environmental influences on children's television watching from early to middle childhood. Journal of Developmental and Behavioral Pediatrics, 23, 127-132.

Silver, D., Mijanovich, T., Uyei, J., Kapadia, F., \& Weitzman, B. (2011). Lifting boats without 
closing gaps: Child health outcomes in distress U.S. cities from 1992-2002. American Journal of Public Health, 101, 278-284.

Suls, J., Martin, R., \& Wheeler, L. (2002). Social Comparison: Why, with whom and with what effect? Current Directions in Psychological Science, 11(5), 159-163.

Tajfel, H., \& Turner, J. C. (1986). The social identity theory of inter-group behavior. In S. Worchel and L. W. Austin (eds.), Psychology of Intergroup Relations. Chicago: Nelson-Hall.

Taverno, S., Rollins, B., \& Francis, L. (2010). Generation, language, body mass index, and activity patterns in Hispanic children. American Journal of Preventative Medicine, 38 , 145-153.

Taylor, A. W., Dal Grande, E., Gill, T. K., Chittleborough, C. R., Wilson, D. H., Grant, J. F., et al. (2006). How valid are self- reported height and weight? A comparison between CATI selfreport and clinic measurements using a large cohort study. Australian and New Zealand Journal of Public Health, 30 (3), 238-246.

US Department of Health and Human Services. (2010). Data 2010: The healthy people 2010 database. Hyattsville, MD. US Department of Health and Human Services, CDC, National Center for Health Statistics; 2004. Available at http://wonder.cdc.gov/data2010/focus.htm.

Wang Y. \& Beydoun, M. A. (2007). The obesity epidemic in the United States - gender, age, socioeconomic, racial/ethnic, and geographic characteristics: A systematic review and meta-regression analysis. Epidemiologic Reviews, 29, 6-28.

Washington, P. S., Reifsnider, E., Bishop, S. L., Ethington, M. D., \& Ruffin, R. E. (2010). Changes in family variables among normal and overweight preschoolers. Issues in Comprehensive Pediatric Nursing, 33, 20-38.

Wolf, L. S., Acevedo-Garcia, D., Subramanian, S. V., Weber, D., \& Kawachi, I. (2010). Subjective social status, a new measure in health disparities research? Do race/ethnicity and choice of referent group matter? Journal of Health Psychology, 15, 560-574.

$\underline{\text { Author Information }}$

Christina M. Granillo, Ph.D

Dept. of Psychology

California State University San Bernardino

*David V. Chavez, Ph.D

Dept. of Psychology

California State University San Bernardino

Phone: 9095375572

E-mail: dchavez@csusb.edu

Donna M. Garcia, Ph.D

Dept. of Psychology

California State University San Bernardino

Kelly Campbell, Ph.D

Dept. of Psychology

California State University San Bernardino

* corresponding author 